\title{
Excision of the ulnar head in patients with rheumatoid arthritis
}

\author{
J. J. RASKER, E. F. M. VELDHUIS, A. J. C. HUFFSTADT, AND \\ R. L. F. NIENHUIS
}

From the Departments of Rheumatology and Plastic Surgery, University Hospital, Groningen, The Netherlands

SUMMARY In 40 patients with rheumatoid arthritis 43 operations for excision of the ulnar head were performed. A follow-up study was performed after 35 months. In 38 patients wrist pain had disappeared completely or almost completely. The function in use, supination and pronation of the wrists, and wrist strength had all much improved. The stability of the radiocarpal joint was good after operation. Only minor complications were seen.

A symmetrical involvement of the wrists is found in $95 \%$ of patients with rheumatoid arthritis (RA). The symptoms usually start in the ulnar part with proliferative synovitis affecting both radioulnar and radiocarpal joints. There is swelling with ligamentous laxity, often resulting in dorsal-ulnar subluxation or dislocation of the ulnar head. Owing to pain and mechanical blocking rotation of the forearm and movements of the wrists are restricted. The adjacent extensor tendons may be involved and may rupture. The condition is presumably further enhanced by the attrition of the dislocated and deformed ulnar head on the tendons during rotational movements.

A characteristic picture based on these changes appears, described ${ }^{1}$ under the name 'caput ulnae syndrome', with the following features: (1) wrist weakness, rotational pain, and limitation of rotation of the forearm; (2) dislocation of the caput ulnae and possible rupture of the long extensor tendons; and (3) soft tender fluctuating swelling. Rana and Taylor $^{2}$ suggested adding to these symptoms: (4) poor grip and reduced function of the hand.

Since one painful joint may thus limit function and use of many adjacent joints, it is important to treat such a joint if possible. The wrist joint is an excellent example of this situation, and when general therapy and perhaps local corticosteroids have failed to improve the condition surgery may be required.

The original description of a distal ulnar resection by Moore $^{3}$ was for traumatic disorganisation of the inferior radioulnar joint. Darrach ${ }^{4}$ performed a

Accepted for publication 26 June 1979

Correspondence to Dr J. J. Rasker, Ziekenhuis Ziekenzorg, De Ruyterlaan 5, Enschede, The Netherlands. subperiostial excision of $3 \mathrm{~cm}$ with preservation of the styloid process and ulnar collateral ligaments, and Dingman $^{5}$ found no difference between extra- and subperiostial excision, with and without ulnar styloid preservation, to relieve symptoms and improve wrist function in derangement of the distal radioulnar joint secondary to trauma. Smith-Petersen et $a l .{ }^{6}$ resected the ulnar head in patients with RA, mostly as part of a technique of arthrodesis. Afterwards resection of the distal end of the ulna was more often undertaken on patients with RA, ${ }^{1-16}$ especially in cases with attrition rupture of the extensor tendons.

Jackson et al. ${ }^{17}$ Rana and Taylor ${ }^{2}$, and Cracchiolo and Marmor ${ }^{18}$ described large series with 'reasonable' results, yet in 1974 Flatt $^{10}$ described the operation as 'rather unsatisfactory'.

\section{Patients and methods}

Of 42 patients with RA who underwent resection of the ulnar head between 1968 and 19732 had died from unrelated diseases and therefore only 40 could be taken into this follow-up study, 11 males and 29 females. Three patients had bilateral resections, 37 unilateral, giving a total of 43 operated wrists. The mean duration of their arthritis was 11.5 years, with mean wrist involvement of 8.8 years in the operated wrists and $5 \cdot 2$ years in the nonoperated wrists. The patients' mean age at control was 54.6 years (range 22-75) and the follow-up period 34.9 months (range 16-60). One patient had possible RA and one definite; all the others had classical RA (ARA grading ${ }^{19}$ ) and were restricted in their daily activities. 
Most wrists also showed severe changes on the $x$-rays. Radiological grading of the wrists is shown in Table 1. Before operation all patients had undergone prolonged conservative treatment, including antimalarials (25 patients), gold (37 patients), analgesic or antiphlogistic drugs (38 patients), and general corticosteroids ( 3 patients), splints, and in 11 cases intra-articular injections of hydrocortisone, before being considered for operation.

All were motivated, co-operative patients with severe wrist pain and loss of function as their main complaints. The wrist function was reduced and motion frequently impaired. Often they could not open doors, handle a kettle, or receive loose change.

All wrists were swollen and in most cases there was a dorsally dislocated ulnar head with painful piano-key sign. This sign is elicited by pressing gently downwards over the dorsally prominent lower end of the ulna.

All patients were investigated extensively by one of us (R.L.F.N.) preoperatively. Postoperative clinical assessment was carried out by a rheumatologist and a surgeon (J.J.R. and E.F.M.V.) who had not operated on anyone in this series. Pain was evaluated at follow-up on a 6-point score (see Fig. 1). The function in use was assessed on a 4-point scale (Table 2).

Hand; and wrists were $x$-rayed preoperatively and at follow-up in 3 directions: antero-posterior, radioulnar, and at 45 degrees. At the final examination an $x$-ray in maximal ulnar and radial deviation was also taken.

$X$-rays were read by a radiologist (T.) and a surgeon (E.F.M.V.), according to an agreed plan and without knowledge of clinical details under 'blind' conditions. Interpretation of osteoporosis

Table $1 \quad X$-ray grading

\begin{tabular}{lccccc}
\hline & \multicolumn{2}{l}{ Operated side } & & \multicolumn{2}{c}{ Nonoperated side } \\
\cline { 2 - 3 } \cline { 5 - 6 } \cline { 5 - 6 } & Pre- & Post- & & Pre- & Post \\
\hline 0 & 0 & 0 & 5 & 5 \\
1 & 1 & 4 & 2 & 0 \\
2 & 3 & 5 & 3 & 2 \\
3 & 39 & 32 & & 27 & 26 \\
4 & 0 & 2 & 0 & 4 \\
& 43 & 43 & 37 & 37 \\
\hline
\end{tabular}

Individual changes in $x$-ray grading

$\begin{array}{llll} & \text { Improved } & \text { Same } & \text { Worse } \\ \text { Operated side } & 8 & 31 & 4 \\ \text { Nonoperated side } & 2 & 26 & 9\end{array}$

0 No abnormalities

1 No destructive changes, osteoporosis may be present, soft tissue swelling

2 Osteoporosis with or without subchondral bone destruction

3 Cartilage and bone destruction, joint deformity

4 Fibrosis or bony ankylosis with grade 3 criteria
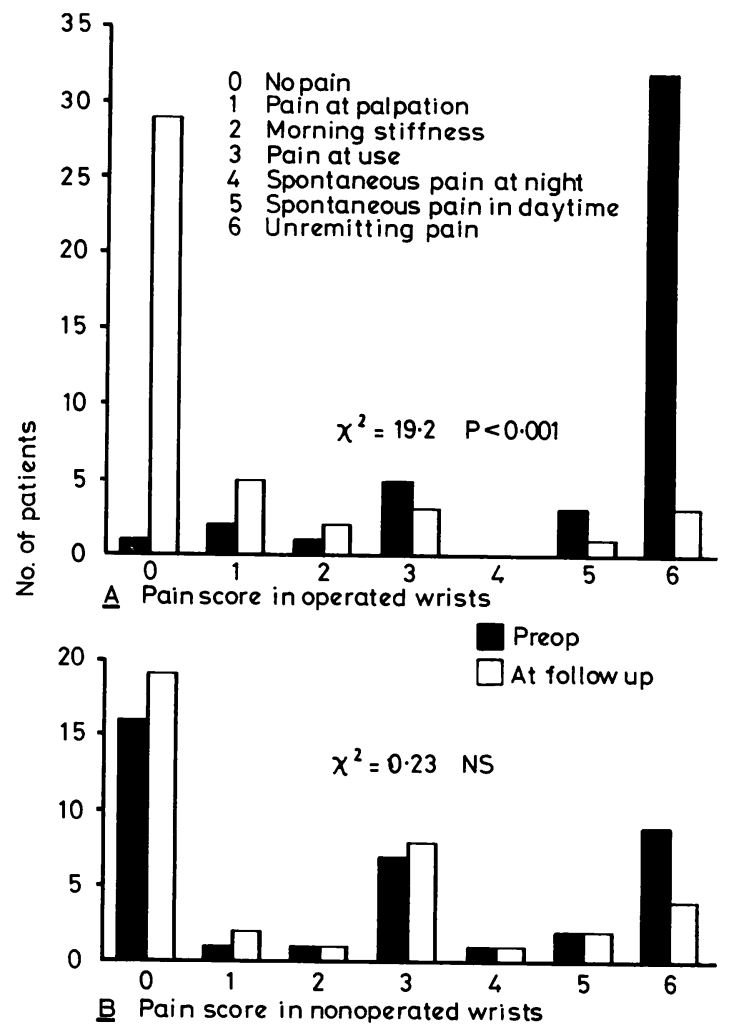

Table 2 Function in use

\begin{tabular}{|c|c|c|c|c|}
\hline & \multicolumn{2}{|c|}{ Operated wrist* } & \multicolumn{2}{|c|}{ Nonoperated wrist ${ }^{* *}$} \\
\hline & Preop & $\begin{array}{l}\text { At } \\
\text { follow-up }\end{array}$ & Preop & $\begin{array}{l}\text { At } \\
\text { follow-up }\end{array}$ \\
\hline $\begin{array}{l}\text { Undisturbed } \\
\text { Undisturbed with }\end{array}$ & 4 & 21 & 14 & 16 \\
\hline pain & 10 & 10 & 11 & 9 \\
\hline Restricted movement & 25 & 12 & 11 & 12 \\
\hline No use & 4 & 0 & 1 & $\mathbf{0}$ \\
\hline
\end{tabular}

*Difference between preop. and at follow-up highly significant $\chi^{2}=14.4, P<0.001$.

**Difference between preop. and at follow-up nonsignificant $\chi^{2}=$ 0.055 , NS.

Table 3 Indications for operation

\begin{tabular}{lc}
\hline Symptom & $\begin{array}{l}\text { Number of } \\
\text { wrists }\end{array}$ \\
\hline Pain only & 1 \\
Pain and synovitis & 8 \\
Pain and limited movement & 3 \\
Pain, limited movement, and synovitis & 24 \\
Pain, synovitis, and extensor tendon rupture & 4 \\
Pain and ulnar and median nerve compression & 1 \\
Limited movement only & 1 \\
Synovitis only & 1 \\
Total & 43 \\
\hline
\end{tabular}


Table 6 Mobility of wrist preoperatively and at follow-up in the nonoperated side $(n=37)$

\begin{tabular}{|c|c|c|c|c|c|c|c|}
\hline & \multicolumn{3}{|c|}{ Preoperative } & \multicolumn{3}{|c|}{ Postoperative } & \\
\hline & 0 & 1 & 2 & 0 & 1 & 2 & \\
\hline Supination & 18 & 16 & 3 & 26 & 6 & 5 & $\left(\chi^{2}=3 \cdot 6, \mathrm{NS}\right)$ \\
\hline Pronation & 19 & 15 & 3 & 24 & 10 & 3 & $\left(\chi^{2}=1.4, N S\right)$ \\
\hline Ulnar deviation & 8 & 18 & 9 & 9 & 17 & 11 & \\
\hline Radial deviation & 8 & 17 & 10 & 5 & 19 & 13 & \\
\hline Dorsiflexion & 8 & 18 & 9 & 9 & 17 & 11 & ( 2 not noted preop.) \\
\hline Palmar flexion & 9 & 20 & 8 & 8 & 20 & 8 & \\
\hline
\end{tabular}

0 Undisturbed, full range. 1 Slightly disturbed mobility, more than half of full range. 2 Greatly disturbed, less than half of the full range.

Contentedness of patients. When asked whether they would have this procedure performed again, knowing the outcome beforehand, 37 out of 40 patients said they would.

Radiological findings. Radiological improvement of the wrist was found in the operated side in 8 patients and in the nonoperated side in only 2 patients. Radiological deterioration was found in the operated side in 4 cases compared with 9 nonoperated wrists (Table 1).

Ulnar deviation of the carpal bones was no more frequent in the operated wrists than in the nonoperated (Table 7). Postoperatively a dislocation of the ulna was visible on the $x$-ray in $\mathbf{4}$ cases; in three this was regarded as a dorsolateral subluxation, and in the other the dislocation was palmar. Other findings, such as exostoses, bone apposition, regeneration, and calcification, are summarised in Table 7.

Complications. In 13 cases there was a complication after operation. In 8 cases a small region of sensory loss on the dorsum of the hand was seen. In 4 cases wound healing was disturbed by infection (including infected wounds from the other procedures), and in 3 patients there was a haematoma. In 2 patients a further resection was necessary, in

Table 7 Conclusions-radiology

\begin{tabular}{lllll}
\hline & $\begin{array}{l}\text { Non- } \\
\text { operated }\end{array}$ & \multicolumn{2}{l}{ Operated wrists } \\
\cline { 2 - 5 } & & Unilat. & Bilat. & Total \\
\cline { 2 - 5 } & 37 & 37 & 6 & 43 \\
Number of cases & 1 & 2 & - & 2 \\
New bone apposition & 1 & 2 & - & 2 \\
Old bone apposition & 1 & 1 & (resected) & 1 \\
Old bone apposition & 5 & 8 & 1 & 9 \\
$\quad$ disappeared & 7 & 7 & 2 & 9 \\
New exostoses & 5 & 7 & 2 & 9 \\
Old exostoses & 5 & 6 & 2 & 8 \\
New ulnar deviation carpus & -1 & 3 & 1 & 4 \\
Old ulnar deviation carpus & & 1 & - & 1 \\
Regeneration & 1 & 1 & - & 1 \\
Calcification, new & 0 & & & \\
Calcification disappeared & & &
\end{tabular}

one case owing to threatening synostosis and persisting pain in the wrist, while in the other case the piece of ulna removed was too small and pain persisted after operation. Clicking of the ulna was seen 3 times, caused by snapping of the extensor carpi ulnaris tendon over the distal end of the ulna. An unstable radiocarpal joint with carpal ulnar drift was seen in only 1 patient, a waiter who was unable to lift trays after operation, though he was unable to do so before operation either. Dislocation of the ulna was seen before operation in 15 cases and at follow-up in 4 out of 43 wrists.

\section{Discussion}

The most important conclusion of this study is that pain in the radioulnar joint may be a good indication for this operation and that the operation can be performed without impairing wrist function and wrist mobility. Wrist mobility, especially supination and pronation, are in fact improved after operation.

The function in use and mobility of the wrist are surprisingly good after operation, and often people can use their hands better. This is not surprising when one realises that rotational pain and reduction of movement are important factors in limiting the use of the hand in such common everyday movements required for washing, dressing, turning the handles of doors, etc. A painful and badly functioning wrist will at the same time contribute to the inactivity of the adjacent joints. The grip strength was not studied in our group of patients, as the many operations performed on metacarpophalangeal and proximal interphalangeal joints might have biased our results. In our series the strength of the wrist was generally unchanged or slightly improved subjectively. Cracchiolo and Marmor ${ }^{18}$ found increased strength in $60 \%$. Møller ${ }^{20}$ describes a reduction in 21 out of 47 cases, but the fact that he removed 3-4 cm of the distal ulna may have influenced his results. It does not appear to be necessary to combine the operation with radius-head resection to obtain a good supination, as suggested by Jackson et al. ${ }^{17}$

Radiological examination showed improvement in a number of operated wrists, significantly more than in those not operated on. This is at variance with the findings of Rana and Taylor. ${ }^{2}$ We did not observe migration of carpal bones into the space produced by resecting the ulnar head, and ulnar deviation of the carpal bones was found equally in operated and nonoperated wrists. Ulnar regeneration was found in 4 cases but did not give rise to complaints.

Our series differed from earlier reports in that only a few (3 out of 40) patients were treated with 
long-term corticosteroids. This might be an explanation for the fact that joint laxity was less frequently seen in our series. It is known that laxity in metacarpophalangeal joints and neck are more frequently observed in steroid treated patients. ${ }^{21}$ In our series no operations were performed on the radial head, and no fixation of the ulna on the radius was carried out. This fixation of the ulna is apparently not necessary to obtain good stability.

The stability is good after operation, which is in keeping with the fact that the distal end of the ulna does not give support to the bones of the carpus. Marmor $^{16}$ states that the stability is probably better when between 1 and $1.5 \mathrm{~cm}$ is removed from the distal end of the ulna and also the styloid process and triangular disc. When more than $1.5 \mathrm{~cm}$ is removed it tends to cause instability, ${ }^{22}$ but $\mathbf{M ø l l e r}^{20}$ did not observe any unstable joints, even though he removed $3-4 \mathrm{~cm}$. Our findings are in keeping with Møller's. Ulnar dislocation of the wrist is seen after this operation, but in our series it is just as frequently observed in nonoperated wrists as in operated wrists. It is possible that this phenomenon is due to RA itself rather than to the operation.

A snapping sensation was seldom seen in our patients. Rana and Taylor ${ }^{2}$ found it in 23 out of 86 wrists and Møller ${ }^{21}$ in 16 out of 45 , but in their patients the symptoms disappeared within the first year. Jackson et al. ${ }^{17}$ suggested a fixation of the carpi ulnaris tendon to the ulna to prevent it from flicking over the ulnar stump during certain wrist movements, but from the result of our series it appears that this procedure is not necessary to prevent a snapping sensation.

We are indebted to Dr C. J. P. Thijn for reading the $x$-rays and to the plastic surgeons Dr G. Heybroek and Dr E. W. Sauer.

\section{References}

1 Bäckdahl M. The caput ulnae syndrome in rheumatoid arthritis. Acta Rheumatol Scand 1963; Suppl. 5.

2 Rana N A, Taylor A R. Excision of the distal end of the ulna in rheumatoid arthritis. J Bone Joint Surg 1973; 554B: 96-105.

3 Moore E M. Three cases illustrating luxation of the ulna in connection with Colles' fracture. Med Record $1880 ; 17: 305$.

4 Darrach W. Anterior dislocation of the head of the ulna. Ann Surg 1912; 56: 802-3.

5 Dingman P U C. Resection of the distal end of the ulna (Darrach operation): an end result study of twenty-four cases. J Bone Joint Surg 1952; 34A: 893-900.

6 Smith-Petersen M N, AuFranc O E, Larson C B. Useful surgical procedures for rheumatoid arthritis involving joints of the upper extremity. Arch Surg 1943; 46: 76470.

7 Straub L R, Wilson E H. (1956). Spontaneous rupture of extensor tendons in the hand associated with rheumatoid arthritis. J Bone Joint Surg 1956; 38A, 1208-17.

8 Ehrlich G E, Patterson L T, Sokoloff L, Bunim J J. (1959). Pathogenesis of rupture of extensor tendons at the wrist in rheumatoid arthritis. Arthritis Rheum 1959; 2: 33246.

9 Henderson E D, Lipscomb P R. Surgical treatment of rheumatoid hand. JAMA 1961 ; 175 : 431-6.

10 Flatt A E. The Care of the Rheumatoid Hand. St. Louis: Mosby, 1974.

11 Bäckdahl M. (1966). Hand surgery in rheumatoid arthritis. In: Gibson $\mathrm{T}$, ed. Modern Trends in Plastic Surgery. London, Butterworths.

12 Clayton M L. Surgical treatment at the wrist in rheumatoid arthritis. J Bone Joint Surg 1965; 47A: 741-50.

13 Lipscomb P R. Synovectomy of the wrist for rheumatoid arthritis. JAMA 1965; 194: 655-9.

14 Vaughan-Jackson $O \mathrm{~J}$. Rupture of extensor tendons by attrition at the inferior radio-ulnar joint. $J$ Bone Joint Surg 1948; 30B: 528-30.

15 Vaughan-Jackson $O \mathrm{~J}$. Rheumatoid hand deformities considered in the light of tendon inbalance. $J$ Bone Joint Surg 1962; 44B: 764-75.

16 Marmor L. Surgery of the rheumatoid elbow. Follow-up study on synovectomy combined with radial head excision. J Bone Joint Surg 1972; 54A: 573-8.

17 Jackson I T, Milward T M, Lee P, Webb J. Ulnar head resection in rheumatoid arthritis. Hand $1974 ; 6: 172-80$.

18 Cracchiolo A III, Marmor L. Resection of the distal ulna in rheumatoid arthritis. Arthritis Rheum 1969; 12: 415-22.

19 Steinbrocker O., Traeger C H, Batterman R C. Therapeutic criteria in rheumatoid arthritis. JAMA 1949; 140: 659-62.

20 Møller M. Forty-eight cases of caput ulnae syndrome treated by synovectomy and resection of the distal end of the ulna. Acta Orthop Scand 1973; 44: 278-82.

21 Rasker J J, Cosh J A. Radiological study of cervical I spine and hand in patients with rheumatoid arthritis of $O$ 15 years' duration: An assessment of the effects of corticosteroid treatment. Ann Rheum Dis 1978; 37: 529- م 35.

22 Ansell B M, Arden G P, Harrison S H. The results of $\mathrm{N}$ ulna styloidectomy in rheumatoid arthritis. Scand $J$ N Rheumatol 1974; 3: 67 (abstr.) 